\title{
Numerical study of seismic behavior of Composite Steel Plate Shear Walls with flat and corrugated plates
}

\section{Estudio numérico del comportamiento sísmico de la pared de corte de placas de acero compuesto, con placas planas y corrugadas}

Hossein Khosravi (Main and Corresponding Author)

Department of Civil Engineering, Hakim Sabzevari University

Sabzevar 9617976487-397 (Iran)

H.khosravi@hsu.ac.ir

\section{Sayed Shoaib Mousavi}

Department of Civil Engineering, Neyshabur Branch, Islamic Azad University, Neyshabur (Iran)

Shoaib.mousavi@nezammohandesi.ir

\author{
Gholamreza Tadayonfar \\ Department of Civil Engineering, Hakim Sabzevari University \\ Sabzevar 9617976487-397 (Iran) \\ r.tadayon@hsu.ac.ir
}

Manuscript Code: 666

Date of Acceptance/Reception: 06.06.2017/10.08.2015

DOI: 10.7764/RDLC.16.2.249

\begin{abstract}
Composite Steel Plate Shear Wall (CSPSW) is a resistant system to lateral forces with suitable performance which can be utilized by corrugated trapezoidal plates enhancing the stiffness of shear wall. In this study, when the space between the corrugations of trapezoidal plates is either filled or empty, the deformability, stiffness and other seismic parameters of Composite Steel Plate Shear Wall have been studied by Abaqus software. The use of CSPSW with corrugated trapezoidal plate with horizontal and vertical corrugations when the space between the corrugations of Infill plate and concrete layer is empty exhibits more deformability as compared to just the same system when the space has been filled with concrete layer. In fact, applying this application detail in CSPSW with corrugated trapezoidal plate is believed to improve the behavior of this lateral resistant system. If we use trapezoidal plate in CSPSW, it would be recommended that the space between corrugations and concrete layer to be empty.
\end{abstract}

Key words: Composite Steel Plate Shear Wall (CSPSW), Flat and Corrugated Plates, Seismic Behavior.

\section{Resumen}

La pared de corte de placas de acero compuesto (Composite Steel Plate Shear Wall - CSPSW) es un sistema resistente a fuerzas laterales con un rendimiento adecuado que puede ser utilizado por placas trapezoidales corrugadas que aumentan la rigidez de la pared de corte. Este estudio utiliza el software Abaqus, para determinar el espacio entre las corrugaciones de las placas trapezoidales cuando este está lleno o vacío, la deformabilidad, la rigidez y otros parámetros sísmicos de la pared de corte de placas de acero compuesto. El uso de CSPSW con placa trapezoidal corrugada con corrugaciones horizontales y verticales cuando el espacio entre las ondulaciones de la placa de relleno y la capa de hormigón está vacía presenta más deformabilidad, en comparación con el mismo sistema cuando el espacio ha sido llenado con capa de hormigón. De hecho, su aplicación en CSPSW, con placa trapezoidal corrugada se cree que mejora el comportamiento de este sistema resistente lateral. Si se utiliza la placa trapezoidal en CSPSW, se recomienda que el espacio entre las corrugaciones y la capa de concreto esté vacío.

Through combining steel shear wall with concrete shear wall, structure researchers could in addition to removing the side load resisting systems deficiencies in structures, provide also a new system in order to deal with the structure forces named as composite steel plate shear wall (CSPSW). In CSPSW, a reinforced concrete layer places around one or both sides of the steel plate. Stud shear connectors connect filler steel plate and reinforced concrete layer together. In this state, occurrence of buckling before submitting steel plate is prohibited and steel plate resists in CSPSW until the point of submission and the flow of steel. The concrete layer is an insulation of moisture and heat and protects steel shear wall against fire.

Studies on lateral resisting systems have revealed that presence of concrete layer leads to more proper distribution of tension resulted in steel plate and consequently diagonal tension lines in a broader domain. This behavior improves the system performance and maximizes the shear capacity of steel shear wall (Rahai \& Hatami, 2009). 
Scholars at Berkeley University investigated CSPSW behaviors. They aimed to specify and explain seismic design tips. They could present some values for coefficients of the system behavior. The results indicated appropriate performance of CSPSW in controlling and formation of a diagonal tension field (Astaneh-Asl, 1998).

By presenting an experiment on CSPSW, Zhao and Astaneh-Asl (2004) concluded that in models with a gap between concrete layer and boundary parts of the beam and the column there is more deformability than models without this gap.

Investigation of system of steel plate shear wall with corrugated plate by Tipping and Stojadinovic (2008) suggested the use of shear wall with corrugated plate for residential buildings with light cold rolled frames. They believed that using this system increases the shear capacity of steel plate shear wall. They presented a series of design parameters for accurate design of steel plate shear wall with corrugated plate for residential buildings with cold rolled frames.

In 2008, Sun, Liu, \& Li (2008), numericall invetsigated the composite steel shear walls and they proposed trannverse bar model on the basis of mechnisim and break mode of the composite steel plate shear wall.

The impact of symmetric and asymmetric buckling modes, complete bracing of the tensile field due to the in-plane bending, the ratio of plane slope direction on the behavior of tensile field and buckling factor of the steel shear plate walls was studied (Memarzadeh, Azhari, \& Saadatpour, 2010).

The tensile and energy wasting capabilities of the specimens for the thin-skinned metal shear walls was scrutinized (Vatansever \& Yardimci, 2011).

Local elastic buckling coefficients of steel plates in composite steel plate shear walls were determined by Arabzade Moharami, \& Ayazi (2011a).

In another experimental research, the composite steel plate shear walls under shearing load were investigated and the results indicated that the stiffeners of the plate is being determined on the basis of minimum reinforcement for the reinforced-concrete and it should be noted that a concrete of high strength is preferred in order for preventing any possible damage (Arabzadeh, Soltani, \& Ayazi, 2011b).

Qin, Lanhui, Feng, \& Sumei (2011) studies the rigidity ratio impact on the siesmic behavior of composite frame infilled composite steel plate shear walls using non-linear static analysis (push-over) and dynamic analysis (loading history).

Ayazi Ahmadi, \& Shafaei (2012) in a study on CSPSWs naming "The effects of bolt spacing on composite shear wall behavior", the findings depict increasing the distance between bolts would improve the seismic behavior, however, this increase must be limited, because of large distances will cause widespread buckling of the steel plate in free subpanels between bolts and would result in no improvement. By comparing the results in elastic region, it was observed initial stiffness is not affected by changing the distance.

As it was mentioned, with regard to the fact that the reinforced-concrete layer of CSPSW is responsible for controlling the buckling of steel plate filler web, as a result the load-bearing capacity of this layer of reinforced-concrete was ignored during designation of CSPSW for assurance. Therefore, the concrete of this layer will be the same type as the concrete types made of construction recycling and waste materials which will contribute to the environmental protection, although it is a small measure. Several researches have been conducted with a main focus on the use for waste and recycling materials in the construction, among which we can refer to the research accomplished by Sanchez, Oshiro, \& Positieri (2014), who used fragmented recycled plastics in the concrete preparation.

About the difference in steel shear wall and CSPSW performance, we should mention here that in both systems, the steel shear wall and CSPSW, we observe post-buckling phenomenon. In state steel shear wall, buckling is overall and uses resistance of a limited area of steel plate, while in CSPSW buckling changes from a general form to a positional state and as a result utilizes entire resistance of steel plate (Rahai \& Hatami, 2009).

Considering investigation on CSPSW, we see that no independent study has been performed so far about rippling plate in CSPSW. So, the present study for the first time through integrating steel shear wall with rippling plate and CSPSW and creating a CSPSW with rippling plate, the researches generated an innovative plan.

In this study, CSPSW stands for Composite Steel Plate Shear Wall, F-CSPSW for Composite Steel Plate Shear Wall with flat plate, CH-CSPSW for Composite Steel Plate Shear Wall with corrugated trapezoidal plates with horizontal 
corrugations, and CV-CSPSW for Composite Steel Plate Shear Wall with corrugated trapezoidal plates with vertical corrugations.

Numerical study of CSPSW Samples

\section{Validation of Analytic Model by Test Model}

The CSPSW of Zhao and Astaneh-AsI $(2004 ; 2007)$ was modeled by Abaqus software to ensure the accuracy of the results of analysis and we found out that the numerical results were in good agreement with experimental results. Since the behavior of consumed steel was considered as double line, difference with test results is inevitable. In Figure 1-a, computerized model, and in Figure 1-b, the comparison of Push-Over response of CSPSW model by Zhao and Astaneh-Asl, respectively, were shown.

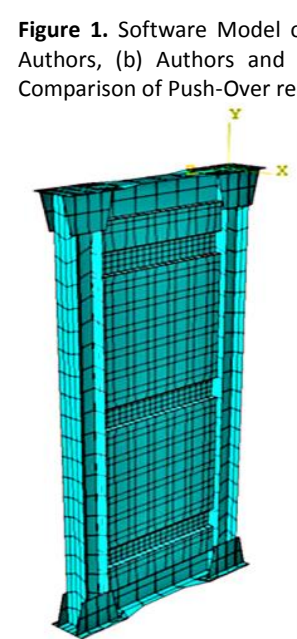

(a)

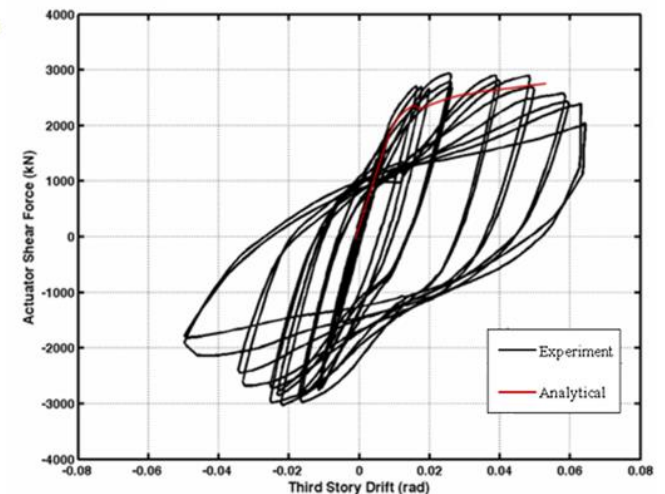

(b)

As shown in Figure1-b, pushover graph is close to the experimental test of CSPSW.

In the present study to ensure the calibration of software with respect to the hysteresis response of numerical models, the one floor experimental sample of steel shear wall, Vian and Bruneau (2006) was utilized. Since the provided models in this research all are in one story format, the finite element software Abaqus used to model them. The results illustrate very good accuracy of hysteresis response of the numerical model to the experimental sample. Figure 2 shows comparison between hysteresis responses of numerical model with experimental sample.

Figure 2. Experimental model of Vian and Bruneau (2006). Source: (a) Authors, (b) Vian \& Bruneau (2006), (c) Authors and Vian \& Bruneau (2006). (a) Reference software model by the reference (Vian \& Bruneau, 2006); (b) Details of created experimental model by the reference (Vian \& Bruneau, 2006); c) Comparing hysteresis response of numerical model with reference experimental sample by reference (Vian \& Bruneau, 2006).

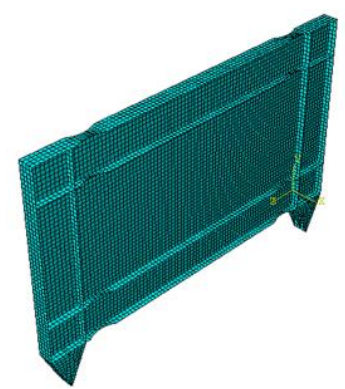

(a)

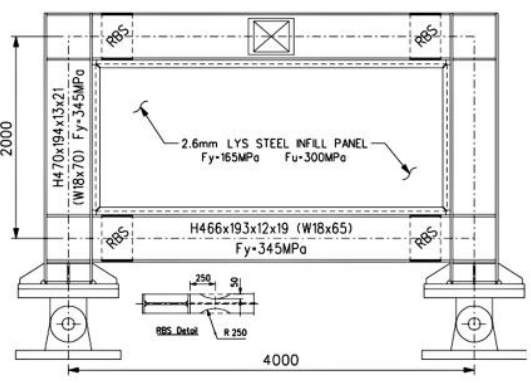

(b)

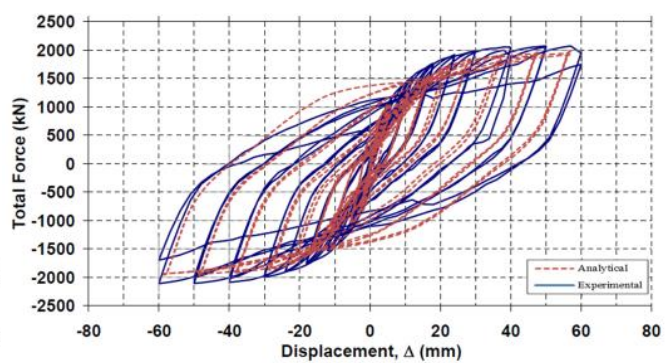

(c)

\section{Modeling of CSPSW Samples}

In this paper, 5 samples of CSPSW with flat plate and corrugated trapezoidal plates with horizontal and vertical corrugations have been modeled by Abaqus software. 
In all of samples, height, span and thickness of steel plates are constant and the shape of steel plate (flat or corrugated), corrugation direction in corrugated trapezoidal plate, as well as the space between the corrugations of Infill plate and concrete layer are considered as variables. Table 1 shows the details of used samples in this study.

Table 1. Features of the models. Source: Authors.

\begin{tabular}{cccccccc}
\multicolumn{8}{c}{ Table 1. Features of the models. Source: Authors. } \\
$\begin{array}{ccccccc}\text { Samples } \\
\text { type }\end{array}$ & System & $\begin{array}{c}\text { Samples } \\
\text { name }\end{array}$ & $\begin{array}{c}\text { Height } \\
(\mathrm{m})\end{array}$ & $\begin{array}{c}\text { Span } \\
(\mathrm{m})\end{array}$ & $\begin{array}{c}\text { Thickness } \\
(\mathrm{m})\end{array}$ & $\begin{array}{c}\text { Plate } \\
\text { type }\end{array}$ & $\begin{array}{c}\text { The } \\
\text { orientation } \\
\text { of plate's } \\
\text { corrugate }\end{array}$ \\
\hline CSPSW & With & CF & 3 & 3 & 0.0045 & Flat & None \\
& Gap & CTVER & 3 & 3 & 0.0045 & Trapezoid & Vertical \\
& Without & CTHOR & 3 & 3 & 0.0045 & Trapezoid & Horizontal \\
& CCTHOR & 3 & 3 & 0.0045 & Trapezoid & Horizontal \\
& Gap & CCTVER & 3 & 3 & 0.0045 & Trapezoid & Vertical \\
\hline
\end{tabular}

In Table 1, a number of Latin letters has been used to name the samples. The first letter refers to the fact that the sample type is CSPSW. It's been shown in all models by the letter C. Second letter refers to the type of plate in CSPSW models in which F stands for flat plate and T for corrugated trapezoidal plate. In models with corrugated trapezoidal plate, to realize the corrugation direction, VER and HOR have been used to refer to the vertical and horizontal corrugations, respectively. The important point is that one $C$ has been used between the two starting letters $C$ and $T$ to name special models of CSPSW with corrugated trapezoidal plate in which the space between the corrugations of trapezoidal plate has been filled by a concrete cover.

In all models, the height and span of CSPSW is set at $3(\mathrm{~m})$ and thickness of steel plate in different flat and corrugated trapezoidal shapes has been considered to be $4.5(\mathrm{~mm})$. Boundary beams and columns have been modeled in the

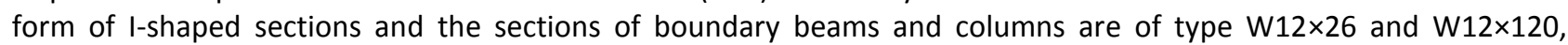
respectively (Figure 3-a). The connection of steel plate to the boundary parts of beam and column was supposed to be jointly and connection of beam to column was rigid. A plan of modeled CSPSW has been shown in Figure 3-b.

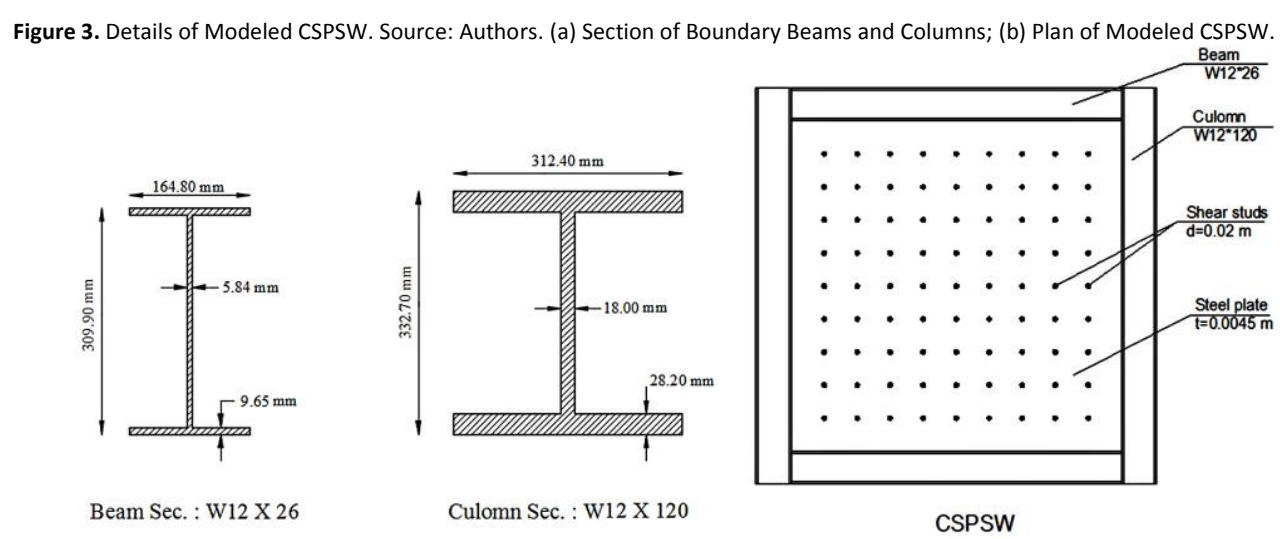

(a) (b)

Flat steel plate, corrugated trapezoidal plate and boundary parts of beam and column have been modeled by Shell (S4R: A 4-node doubly curved thin or thick shell, reduced integration, hourglass control, finite membrane strains.) element, a four-joint, two-curve element. In this element, every joint contains 6 degrees of freedom, including three transfer and three rotation degrees. Since the concrete is one of the items whose non-linear behavior has always attracted the attention and various models have been proposed to determine it, it's necessary to consider three important issues. Firstly, concrete behavior is completely different in pressure and tension; second is the crack issue in concrete; and thirdly, the way we should model the concrete behavior when it passes from pressure to tension and vice versa. Of course, the third item receives more attention in cyclic loading (two-way). Therefore, Solid (C3D8R: An 8-node linear brick, reduced integration, hourglass control) element was used to model 3-dimensional concrete layer. This element has the capability of modeling the cracks caused by stress and yielding in pressure. It also has the capability of modeling concrete layer on the steel plate. This element can be defined by 8 joints each of which has three degrees of transfer freedom in 3 dimensions. 
Concrete behavior can be easily modeled by the existing relationships, but what is of great importance is modeling in successive mode. In this case due to the crack formation and its extension in cyclic loadings, concrete behavior is completely different with steel's.

Smearing cracking model was used to model the concrete layer. In this method, the waste potential is a function of stress and a crack occurs when stresses reach the yielding point. The crack surfaces were also assumed to be perpendicular to the direction of maximum tensile main stress; so in the case of compressive stresses no damage is caused and the concrete response is modeled by elastic-plastic theory. Concrete layer is considered to be $100 \mathrm{~mm}$ thicknesses and Bars with a diameter of $10 \mathrm{~mm}$ with $155 \mathrm{~mm}$ spacing have been used, the ratio of reinforcement to the consumed concrete in this layer is $0.92 \%$. For connecting the concrete layer to filer steel layer, 81 stud shear connectors were utilized. Assuming the full connection of concrete layer with filler steel plate, the effect of this behavioral homogeneity in the place of nodes corresponding to two parts (concrete layer and filler steel plate) in the shown positions of stud shear connectors are illustrated in Figure 3.

To model these shear studs, Solid (C3D8R) model has been used. To model the concrete reinforcement, Truss (T3D2: A 2-node linear 3-D truss.) element has been used and concrete layer protecting bars in all samples are considered to be $30 \mathrm{~mm}$ in diameter. The features of reinforced concrete used for modeling the concrete layer have been offered in Table 2.

Table 2. Features of the Reinforced Concrete. Source: Authors.

\begin{tabular}{|c|c|c|c|c|c|c|c|c|}
\hline \multicolumn{4}{|c|}{ Concrete } & \multicolumn{5}{|c|}{ Rebar } \\
\hline $\begin{array}{r}\mathrm{f}_{\mathrm{c}}^{\prime} \\
(\mathrm{MPa})\end{array}$ & $\begin{array}{c}\text { Thickness } \\
(\mathrm{m})\end{array}$ & $v$ & $\begin{array}{l}\text { Concrete } \\
\text { Cover }(\mathrm{m})\end{array}$ & $\mathrm{E}(\mathrm{Pa})$ & $\begin{array}{c}\text { Rebar } \\
\text { dia. }(\mathrm{m})\end{array}$ & $\begin{array}{c}\text { Rebar } \\
\text { spacing }(\mathrm{m})\end{array}$ & $\begin{array}{l}\text { Reinf. } \\
\text { Ratio }\end{array}$ & $v$ \\
\hline 28 & 0.1 & 0.2 & 0.03 & $2.1 \mathrm{E} 11$ & 0.01 & 0.155 & $0.92 \%$ & 0.3 \\
\hline
\end{tabular}

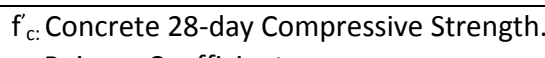

v: Poisson Coefficient.

E: Elasticity Modulus.

In all samples, the steel used for boundary parts of beams and columns and steel plate is of yielding stress of 240 ( $\mathrm{MPa}$ ) and ultimate stress of 360 (MPa). The steel behavior model as double line and the compressive strength of 28day concrete is considered $28(\mathrm{MPa})$. Features of consumed steel in modeling boundary parts of beams and columns, steel plate, rebar and shear studs are listed in Table 3.

\begin{tabular}{ccccc}
\multicolumn{5}{c}{ Table 3. Features of the Consuming Steel. Source: Authors. } \\
\hline & $\mathrm{f}_{\mathrm{y}}(\mathrm{Pa})$ & $\mathrm{fu}_{\mathrm{u}}(\mathrm{Pa})$ & $\mathrm{E}(\mathrm{Pa})$ & $v$ \\
\hline $\begin{array}{c}\text { Boundary beams and } \\
\text { columns, steel plate, rebar } \\
\text { Shear studs }\end{array}$ & $2.4 \mathrm{E} 8$ & $3.6 \mathrm{E} 8$ & $2.1 \mathrm{E} 11$ & 0.3 \\
& $5.7 \mathrm{E} 8$ & $8.1 \mathrm{E} 8$ & $2.1 \mathrm{E} 11$ & 0.3 \\
\hline $\begin{array}{l}\mathrm{f}_{\mathrm{y}: \text { Yielding Tension. }} \\
\mathrm{f}_{\mathrm{u}} \text { Ultimate Tension. }\end{array}$ & & & & \\
\end{tabular}

The important point in CSPSW models with corrugated trapezoidal plate with vertical and horizontal corrugations is the fact that the reinforced concrete layer is joined to corrugated trapezoidal plate by shear studs in a way that the space between the corrugations of Infill plate in CSPSW is considered as a variable according to Figure 4. As you can see in Figure 4-a in a number of samples, this space is open and in some others (as shown in Figure 4-b) it has been closed by a concrete layer. As there is the possibility of joining the concrete layer to steel plate in a precast way due to the low thickness of reinforced concrete, we first deal with the behavior of samples in which this space is open and then examine the effect of its opening or closing in CSPSW models. The details for trapezoidal plate which has been used in software modeling of CSPSW models have been given in Figure 4-c.

Figure 4. Application Details of CSPSW with Corrugated Trapezoidal Plate. Source: Authors. (a) CSPSW Model with Empty Space between Corrugations; (b) CSPSW Model with Filled Space between Corrugations; (c) Corrugated Trapezoidal Plate Used in Modeling CSPSW.

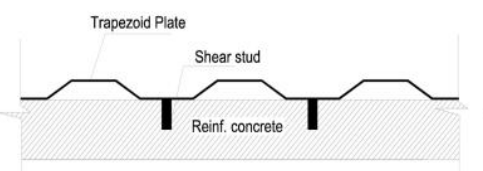

(a)

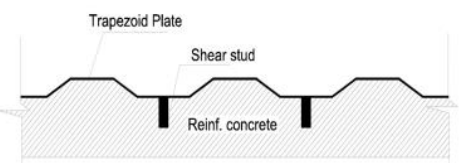

(b)

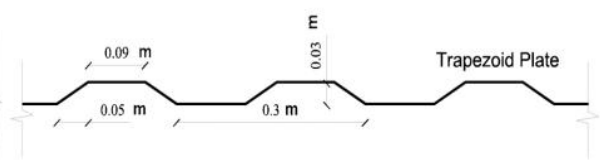

(c) 


\section{Boundary Conditions}

In all samples, out-of-plane degrees of freedom are closed in boundary parts of beam and column, and out-of-plane freedom degrees of rotation are open in steel plate in which buckling of the plate is possible. The connection between concrete and steel plate is provided by shear studs. All of the freedom degrees including displacement and rotation are fixed in the basic level and bars are embedded in the concrete. Smearing cracking has been used to model the concrete and the friction produced between concrete and steel plate is considered negligible. The connection of steel plate to the boundary parts of beam and column was supposed to be jointly and connection of beam to column was rigid.

Behavior of the models is based on non-linear static analysis (Push-Over), including the non-linear geometry and materials, and the failure criterion is Von-Mises theory. Boundary beams and columns have been modeled in the form

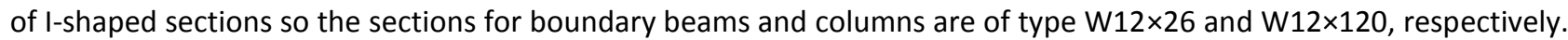
In order to decrease the numerical errors in the models, the size of elements was selected as small as possible. To get the hysteresis response in all models a lateral drift has been applied to an extent so that the models can enter the plastic region. For this purpose they've been loaded at the joints where steel plate is joined to the boundary parts of beam and column. The cyclic loading curve has been shown in Figure 5.

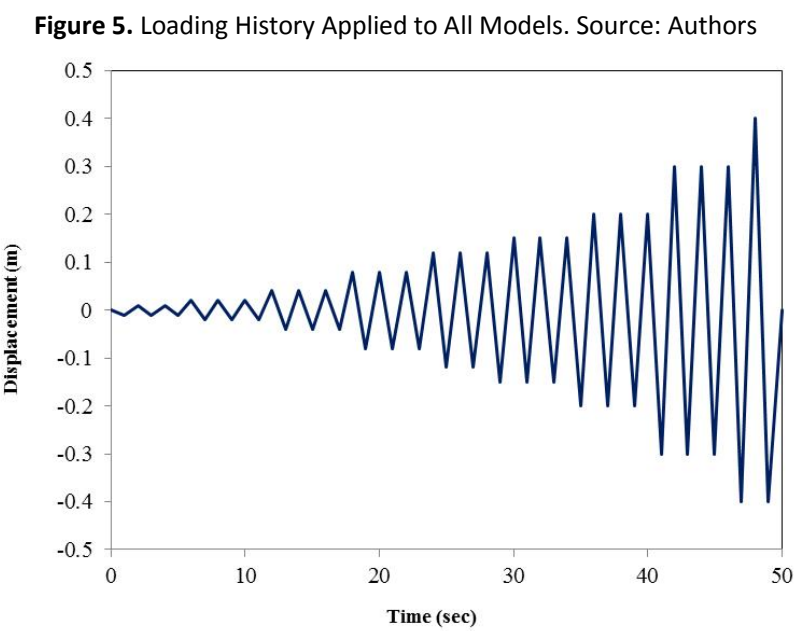

Concrete alone has no ability to withstand tensile stresses as a compressive stress and its tensile strength is low. To compensate for this problem steel rebar are used. The concrete response initiate with traction through opening and expansion of cracks. The concrete reaction is linear until it reaches its tensile resistance. They are with very tiny cracks. By increase of loading, resistance a decrease significantly, cracks expands until it fails in final strain.

Smearing cracking model is one of provided models for concrete are used mostly in finite element software. Physically, the Smearing cracking model can be described by a series of tiny cracks. In this model, for formation of cracks, they are defined using the main maximum tensile stress. When a crack is formed, a coordinate system attaches to the cracks that one of axis locates in perpendicular direction to the surface. Then, for this axes a stress-strain law are perpendicular together are defined with consideration of strain softening characteristics. This model shows crack in concrete in form of a series of latitudinal parallel cracks in the element.

In natural state, when a material undertakes loading greater than its resistance, cracks initiates from this point in which the material has a deficiency or non-uniformity of material. When a sample is modeled using mechanics of continues media, we usually assume that the material has no non-uniformity or deficiency. Therefore, in these models for formation and expansion of cracks, most often loss potential which is also known as submit level or collapse level is used. The collapse track is defined through derivative potential with regard to tension or strain tensor. The loss potential could be either a function of tension or a function of strain.

In the Smearing cracking model, loss potential is a function of tension that is to say, crack takes place when tension reaches the point of submission. Moreover, Smearing cracking levels is assumed perpendicular to the maximum direction of main tensile stress. As a result of this, in compressive tension no harm is predicted and the concrete response is modeled using elastic-plastic theory. 
In order to analyze the hysteresis graphs of CSPSW with flat and corrugated trapezoidal plate with vertical and horizontal corrugations, the model provided for the analysis of the hysteresis graphs of SPSW by Memarzadeh has been used (Memarzadeh, 2009). Figure 6 indicates the cyclic model of these researchers.

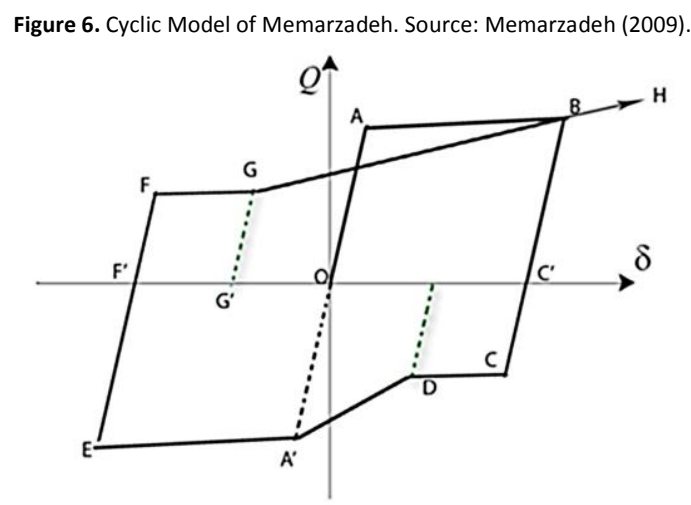

In Figure 6, vector $\mathrm{OAB}$ indicates the primary loading of shear wall in the positive direction. Vector BC' suggests the load of shear wall that is assumed to be parallel to the primary loading vector OA. Vector $\mathrm{CC}^{\prime}$ implies the wall loading on the contrary direction (negative direction). Point $C$ is the place where the shear lateral buckling of Infill plate occurs and point $D$ is the place where diagonal tension field in the Infill plate starts to form again. To locate point $D$, a parallel line to $O A$ is drawn from the middle of line $O C^{\prime}$. Given a loading curve in negative direction (OA'E), cyclic model continues along the vector $\mathrm{DA}^{\prime} \mathrm{E}$ and removing the applied load in negative direction, the cyclic curve, parallel to $O A$, is drawn (EF').

According to this model, the hysteresis curve of CSPSW with flat plate is evaluated. At first, OAB lines were drawn and then the place where the last cycle cut Drift coordinates axis was named $C^{\prime}$. Calculating the center of $O C^{\prime}$ and drawing a parallel line to $O A$, point $D$ was located. This point is the place where diagonal tension field in the Infill plate starts to form again and the areas between $C^{\prime}$ and $D$ are the places where buckling of Infill plate, located by this method, occurs. These areas are drawn for the hysteresis graphs of other models, too. We'll deal with each graph in the following.

Hysteresis response obtained from CSPSW model with flat plate demonstrates deformability and proper seismic behavior of this model during the application of cyclic loads and maximum tolerable basic shear through this model is $2262 \mathrm{kN}$. CSPSW with flat plate is more deformable and is better at absorption and dissipation of energy than CSPSW with corrugated trapezoidal plate with vertical and horizontal corrugations. In Figure 7-a, hysteresis response of CSPSW with flat plate under cyclic loading is shown. Considering the stages mentioned above the method presented by Memarzadeh, points $C$ and D for CSPSW model with flat plate were located. Reproduction of diagonal tension field in the last cycle occurs at the point with a $1300 \mathrm{kN}$ load in the negative direction. Figure 7-b shows the hysteresis curve of CSPSW with flat plate that was evaluated by Memarzadeh's model.

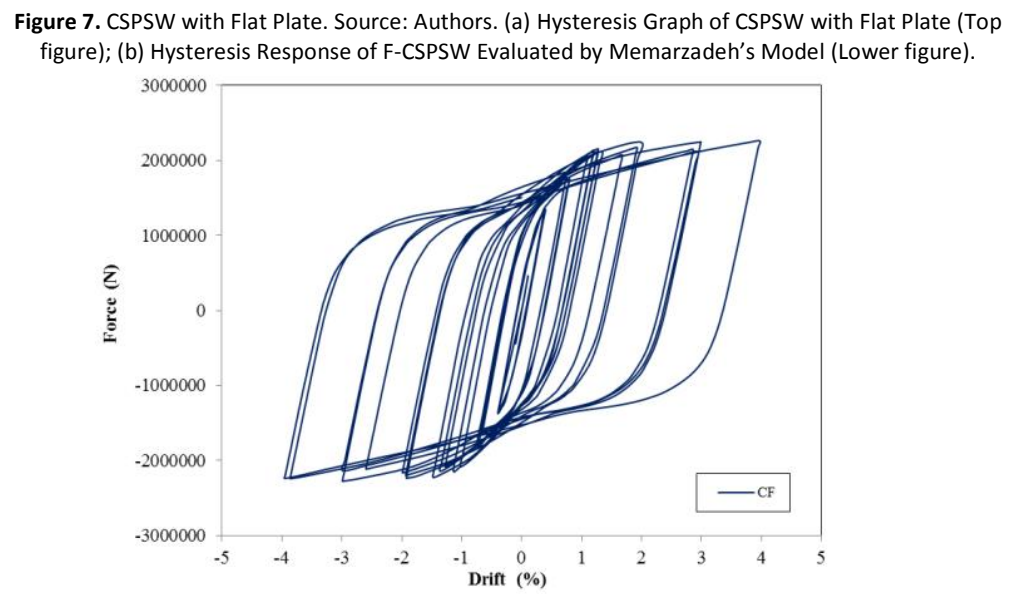




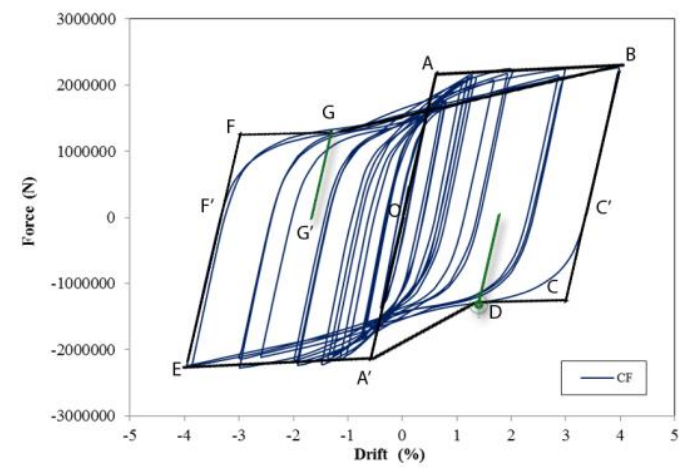

Hysteresis response obtained from analyzing $\mathrm{CH}$-CSPSW indicates the basic shear tolerance of $2542 \mathrm{kN}$ by this system that is definitely much more than F-CSPSW model. In fact the reason for this increase is to control the out-of-plane buckling of steel plate in CSPSW.As we apply greater loads in loading cycles, greater buckling occurs, that this increase is the result of CSPSW strength during loading process, indicating higher strength of this software model compared to F-CSPSW model. Figure 8-a refers to this model's response during cyclic loading. Points C and D, i.e. places where lateral buckling of Infill plate occurs and diagonal tension field of steel plate forms, were located for CSPSW model with corrugated trapezoidal plate with horizontal corrugation by Memarzadeh's method. Reproduction of diagonal tension field in the last cycle occurs at the point with a $1700 \mathrm{kN}$ load in the negative direction. Figure8-b shows the hysteresis response of CSPSW with corrugated trapezoidal plate with horizontal corrugation evaluated by Memarzadeh's model.

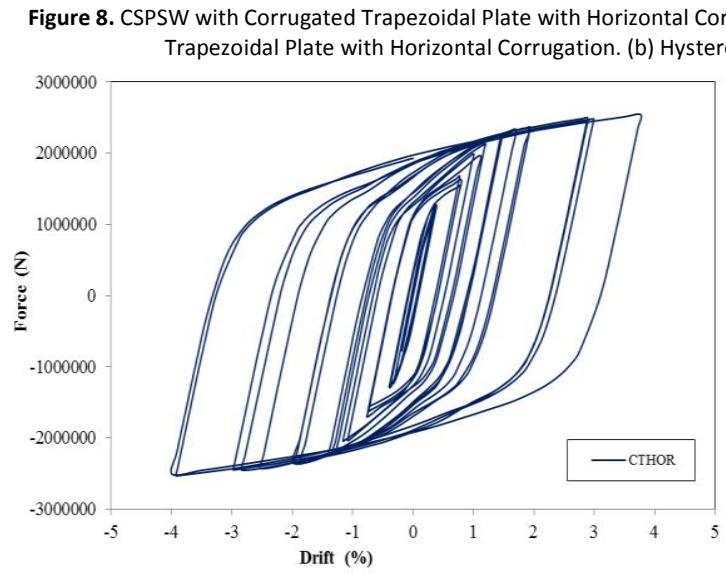

(a)

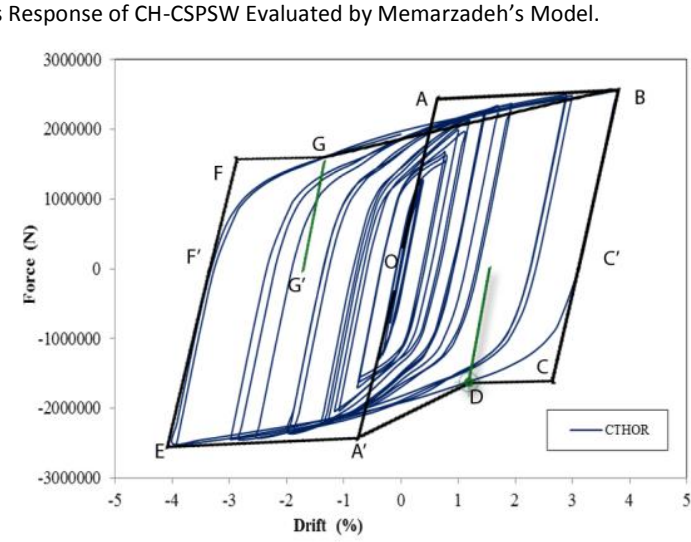

(b)

The response obtained from CSPSW with corrugated trapezoidal plate with horizontal corrugation demonstrates less deformability and more stiffness compared to CSPSW with flat plate. Trapezoidal corrugations of Infill plate, preventing and postponing the out-of-plane buckling of Infill plate, lead to an increase in stiffness and decrease in deformability of this model in comparison to F-CSPSW model. But this model, because of disorder and postponement in the invention of diagonal tension field in Infill plate due to the orientation of Infill plate corrugations and their effect on the invention of diagonal tension field, has less strength than $\mathrm{CH}-\mathrm{CSPSW}$ model. This model's response has been shown in Figure 9-a. Points C and D where lateral buckling of Infill plate occurs and diagonal tension field of steel plate forms were located for CV-CSPSW model by Memarzadeh's method. In this model, reproduction of diagonal tension field in the last cycle occurs at the load of about $1500 \mathrm{kN}$ in the negative direction. Figure 9-b shows the hysteresis curve of CSPSW with corrugated trapezoidal plate with horizontal corrugation, evaluated by Memarzadeh's model. 
Figure 9. CSPSW with Corrugated Trapezoidal Plate with Horizontal Corrugation. Source: Authors. (a) Hysteresis Graph of CSPSW with Corrugated Trapezoidal Plate with Horizontal Corrugation; (b) Hysteresis Curve of CSPSW Evaluated by Memarzadeh's Model.

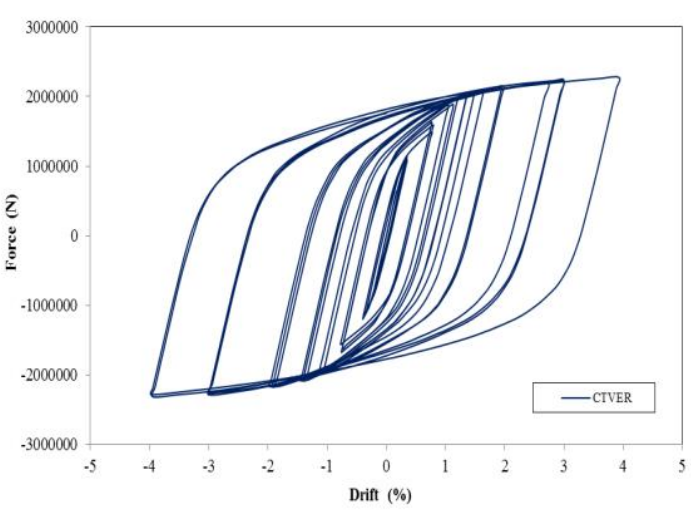

(a)

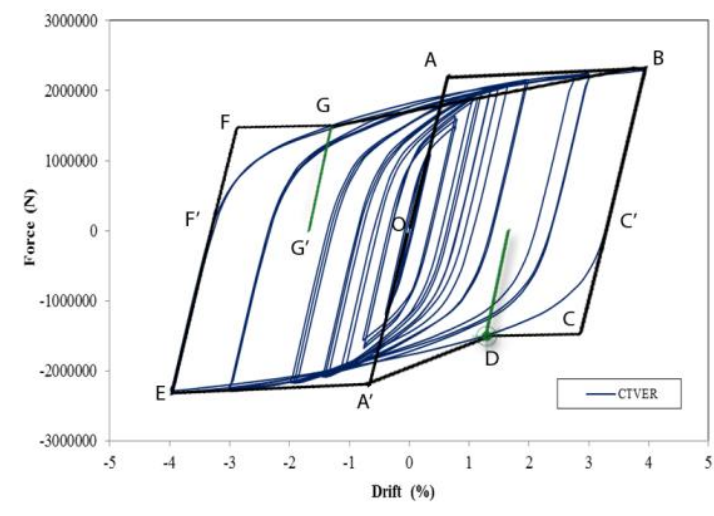

(b)

In general, the strength and stiffness of CSPSW model with corrugated trapezoidal plate with horizontal and vertical corrugations is more than CSPSW model with flat plate. However, CSPSW with flat plate exhibits more deformability and therefore in areas with high seismic risk, it is preferred to CSPSW with corrugated trapezoidal plate. Response of $\mathrm{CH}-\mathrm{CSPSW}$ enjoys the highest rate of stiffness in the graph. It's because of reduced stiffness in CV-CSPSW model compared to horizontal corrugation due to the empty space between the corrugations and concrete layer. While applying loading, it results in some deformation in corrugations in the way they become open compared to horizontal mode, thereby decreasing CSPSW model stiffness.

According to the results obtained from the analysis of the hysteresis graphs of CSPSW model with flat and corrugated trapezoidal plate with horizontal and vertical corrugations by Memarzadeh's model, the formation place phase of outof-plane buckling in Infill plate changes into the reproduction of diagonal tension field; that is, CSPSW with flat plate has less strength than other models of CSPSW, demonstrating better deformability of this lateral anchored system in comparison to other models of CSPSW. This phase transfer occurs for CSPSW with corrugated trapezoidal plate with horizontal corrugation with greater loads of about $1700 \mathrm{kN}$, which involves the highest ratio among other models. Also, this model is less formable than other models.

In minor displacements, CSPSWs with corrugated trapezoidal plate with horizontal and vertical corrugations show similar behaviors. But in major displacements, the behavior of CSPSW with corrugated trapezoidal plate with horizontal corrugation tends to be close to F-CSPSW model, that is because of the probability of deformation in the corrugations of trapezoidal plate due to the opening between them as well as their location and adjacency of formation angel of diagonal tension field to the corrugations' direction in this software sample. F-CSPSW exhibits more deformability than other models. The P- $\Delta$ graph of CSPSW with flat and corrugated trapezoidal plate with horizontal and vertical corrugations has been shown in Figure 10.

Figure 10. Push-Over Curve of CSPSW in Various Types of Plate and Steel Plate. Source: Authors.

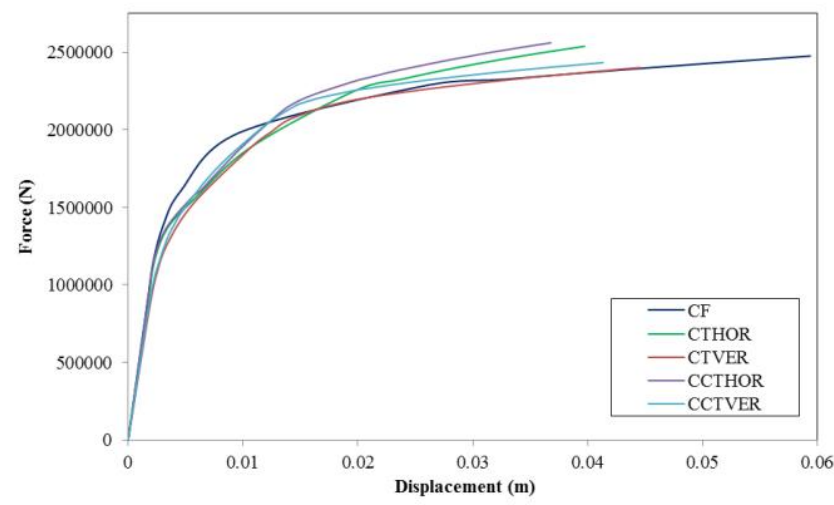

Applying identical lateral loads to CSPSW models with flat and corrugated trapezoidal plate with horizontal and vertical corrugations and making a comparison between the maximum displacement in these models, we found out $42 \mathrm{~mm}$ decrease in displacement and an increase in stiffness as much as $54.5 \%$ in CSPSW with corrugated trapezoidal plate with horizontal corrugation as well as a decrease of $32 \mathrm{~mm}$ in displacement and $36.8 \%$ increase in the stiffness of CSPSW with corrugated trapezoidal plate with vertical corrugation compared to CSPSW with flat plate. In fact, as CT- 
CSPSW involves more stiffness than F-CSPSW, it exhibits better performance in the control of structure's lateral displacements. But it's worth mentioning here that an increase in stiffness can result in a decrease in deformability. However, if we want to deal with the earthquake we need structures with efficient deformability. Stiffness in CSPSW models with flat and corrugated trapezoidal plate with horizontal and vertical corrugations are 30.25, 46.75 and 41.38 $(\mathrm{kN} / \mathrm{mm})$, respectively. In Table 4, the models' stiffness and final displacement ratios with identical load effect at their upper level have been listed.

\begin{tabular}{|c|c|c|c|c|c|c|}
\hline $\begin{array}{r}\text { Samples } \\
\text { type }\end{array}$ & $\begin{array}{l}\text { Samples } \\
\text { name }\end{array}$ & $\begin{array}{c}\text { Operation } \\
\text { description }\end{array}$ & Content & $\begin{array}{c}\text { Stiffness } \\
\text { changes } \\
\text { than flat } \\
\text { plate }\end{array}$ & $\begin{array}{c}\mathrm{K}=\mathrm{F} / \Delta \\
(\mathrm{kN} / \mathrm{mm})\end{array}$ & $\begin{array}{c}\text { Lateral } \\
\text { displacement } \\
\text { redaction } \\
\text { than flat plate }\end{array}$ \\
\hline \multirow[t]{2}{*}{ FCSPSW } & $\mathrm{CF}$ & Displacement $(\mathrm{mm})$ & 119 & None & 30.25 & None \\
\hline & & $\begin{array}{l}\text { Maximum base } \\
\text { shear }(\mathrm{kN})\end{array}$ & 2760 & & & \\
\hline \multirow[t]{2}{*}{ CHCSPSW } & CTHOR & Displacement $(\mathrm{mm})$ & 77 & $54.5 \%$ & 46.75 & -42 \\
\hline & & $\begin{array}{l}\text { Maximum base } \\
\text { shear }(\mathrm{kN})\end{array}$ & 2864 & & & \\
\hline \multirow[t]{2}{*}{ CVCSPSW } & CTVER & Displacement $(\mathrm{mm})$ & 87 & $36.8 \%$ & 41.38 & -32 \\
\hline & & $\begin{array}{c}\text { Maximum base } \\
\text { shear }(\mathrm{kN})\end{array}$ & 2626 & & & \\
\hline
\end{tabular}

In order to investigate the effect of the filling or emptiness of space between corrugations at CH-CSPSW and CVCSPSW, a number of related samples were made and their details are presented in Table 1. To examine this effect, one sample from F-CSPSW and four samples from CV-CSPSW and CH-CSPSW, which in their Infill plate the space between the corrugations of Infill plate and concrete layer is either empty or filled, were modeled by Abaqus software. After analyzing the data obtained from numerical modeling results, the Push-Over graphs of CSPSW were drawn as shown in Figure 9. According to the analysis of Push-Over graph in F-CSPSW and CT-CSPSW models, the filled space between the corrugations of corrugated plate in CSPSW can lead to an increase in stiffness and a decrease in deformability of this resistant lateral system. The stiffness ratio of F-CSPSW and CT-CSPSW models for the identical applied load to the models has been listed in Table 5. As it can be seen in this table, stiffness for CH-CSPSW models when the space between the corrugations of Infill corrugated plate has been filled by the concrete layer has been set at $61.42 \%$ and for the same system with Infill corrugated plate with vertical corrugation when the space between the corrugations of corrugated plate has been filled by the concrete layer is around $43.62 \%$, indicating an increase in the stiffness of these model as compared to F-CSPSW. The empty space between the corrugations of Infill corrugated plate can improve the seismic behavior of CSPSW, thereby increasing the deformability of CSPSW. This application detail can propose some approaches for the invention of a lateral resistant system and improvement of CSPSW behavior when using corrugated trapezoidal plate with horizontal and vertical corrugations.

Table 5. Stiffness Changes of CSPSW in Various Types of Plate and Concrete Layer. Source: Authors.

\begin{tabular}{|c|c|c|c|c|c|}
\hline $\begin{array}{l}\text { Samples } \\
\text { type }\end{array}$ & Operation description & Content & $\begin{array}{l}\text { Lateral } \\
\text { displacement } \\
\text { redaction than } \\
\text { flat plate }(\mathrm{mm})\end{array}$ & $\begin{array}{c}\mathrm{K}=\mathrm{F} / \Delta \\
(\mathrm{kN} / \mathrm{mm})\end{array}$ & $\begin{array}{c}\text { Stiffness } \\
\text { changes than } \\
\text { flat plate (\%) }\end{array}$ \\
\hline \multirow[t]{2}{*}{ CF } & Displacement (mm) & 59 & None & 53.06 & None \\
\hline & $\begin{array}{l}\text { Maximum base shear } \\
\qquad(\mathrm{kN})\end{array}$ & 2476 & & & \\
\hline \multirow[t]{2}{*}{ CTHOR } & Displacement (mm) & 40 & -19 & 79.30 & 49.47 \\
\hline & $\begin{array}{l}\text { Maximum base shear } \\
\qquad(\mathrm{kN})\end{array}$ & 2539 & & & \\
\hline \multirow[t]{2}{*}{ CTVER } & Displacement (mm) & 44 & -15 & 70.66 & 33.18 \\
\hline & $\begin{array}{l}\text { Maximum base shear } \\
\qquad(\mathrm{kN})\end{array}$ & 2401 & & & \\
\hline \multirow[t]{2}{*}{ CCTHOR } & Displacement (mm) & 37 & -22 & 85.65 & 61.42 \\
\hline & $\begin{array}{l}\text { Maximum base shear } \\
\qquad(\mathrm{kN})\end{array}$ & 2561 & & & \\
\hline \multirow[t]{2}{*}{ CCTVER } & Displacement (mm) & 41 & -18 & 76.20 & 43.62 \\
\hline & $\begin{array}{l}\text { Maximum base shear } \\
\qquad(\mathrm{kN})\end{array}$ & 2433 & & & \\
\hline
\end{tabular}


In order to evaluate the effect of filled or empty space between the corrugations of Infill trapezoidal corrugated plate in CH-CSPSW and CV-CSPSW models on their stiffness, the data of stiffness in these models was compared and examined and CV-CSPSW model in the state when the space between the corrugations of Infill corrugated plate and concrete layer have been filled by a concrete cover experiences a $31.45 \%$ increase as compared to when this space is empty. The changes of stiffness for the above system when the corrugations of Infill trapezoidal plate are horizontal and the space between them is filled in comparison to the state when the space is empty is equal to $24.16 \%$. These changes are shown in Table 6.

\begin{tabular}{|c|c|c|c|}
\hline Samples type & Operation description & Content & Stiffness changes \\
\hline \multirow[t]{2}{*}{ CTHOR } & Displacement (mm) & 40 & CCT-HOR Stiffness \\
\hline & Maximum base shear $(\mathrm{kN})$ & 2539 & changes than CTHOR: \\
\hline \multirow[t]{2}{*}{ CCTHOR } & Displacement (mm) & 37 & $24.16 \%$ \\
\hline & Maximum base shear $(\mathrm{kN})$ & 2561 & \\
\hline \multirow[t]{2}{*}{ CTVER } & Displacement (mm) & 44 & CCT-VER Stiffness \\
\hline & Maximum base shear $(\mathrm{kN})$ & 2401 & changes than CTVER: \\
\hline \multirow[t]{2}{*}{ CCTVER } & Displacement (mm) & 41 & $31.45 \%$ \\
\hline & Maximum base shear $(\mathrm{kN})$ & 2433 & \\
\hline
\end{tabular}

Sometimes in order to make the structures with appropriate deformability, we don't need to change the type of lateral anchor system and other design parameters. By applying a series of applications details, we can improve the structural behavior. In general, by considering the effect of the space between corrugations in corrugated plates and concrete layer in CT-CSPSW, it can be concluded that the free space between corrugations and concrete layer in the models above and applying this property as an application detail in making such a lateral anchor system can lead to the improving behavior of CT-CSPSW, thereby increasing the structure's deformability in comparison to the same structure when the space between the corrugations of Infill corrugated trapezoidal plate and concrete layer have been filled by a concrete cover.

\section{Conclusions}

In this paper, CSPSW models with flat and corrugated trapezoidal plate with horizontal and vertical corrugations when the space between the corrugations of Infill trapezoidal plates is either filled or empty were modeled by Abaqus software, some results were obtained which are expressed in following explanations:

- One of the main disadvantages of the steel plate shear wall with corrugated plates, is sudden drop in the lateral load bearing capacity during opening of the web filler corrugated plates due to the impact of lateral loading and deformation of this pate toward to the formation of diametrical tensile field, and such mode can be noted in the capacity diagram of the system as a sudden collapse. In the system proposed by the present research, this problem was overcome using a reinforced-concrete layer.

- CSPSW with flat plate exhibits more deformability than CSPSW with corrugated trapezoidal plate with horizontal and vertical corrugations; therefore, CSPSW with flat plate is preferred to CSPSW with corrugated trapezoidal plate with horizontal and vertical corrugations for the regions of high seismic risk, but in the regions with less seismic risk, CSPSW with trapezoidal plate with horizontal corrugation might be more economic.

- The use of CSPSW with corrugated trapezoidal plate with horizontal and vertical corrugations when the space between the corrugations of Infill plate and concrete layer is empty exhibits more deformability as compared to just the same system when the space has been filled with concrete layer. In fact, applying this application detail in CSPSW with corrugated trapezoidal plate is believed to improve the behavior of this lateral resistant system. If we use trapezoidal plate in CSPSW, it would be recommended that the space between corrugations and concrete layer to be empty.

- Due to the location of critical areas in models in the place of John's steel plate connection place to boundary elements of beam and column, correct implication of plate connection to boundary elements of beam and column at time of designing and implementation, is very important for achieving appropriate performance of this resistant lateral loading system.

- CSPSW with corrugated trapezoidal plate with horizontal corrugation, due to the better control of out-ofplane buckling of Infill steel plate, enjoys more surface strength than Infill steel plate, thereby tolerating more basic shear than CSPSW with flat plate. 
- In composite steel shear wall model with vertical and horizontal waves, if the pace between waves and concrete layer is filled with concrete, ad if the space is empty, $61.42 \%$ and $49.47 \%$ have increased stiffness compared with shear wall with flat plate, respectively.

- In minor displacements in P- $\triangle$ graph, CSPSW models with corrugated trapezoidal plate with horizontal and vertical corrugations indicate obviously similar behaviors, but in major displacements, CSPSW with trapezoidal plate with vertical corrugation demonstrate a similar behavior to CSPSW with flat plate.

\section{References}

Arabzadeh, A., Moharami, H. \& Ayazi, A. (2011a). Local elastic buckling coefficients of steel plates in composite steel plate shear walls. Scientia Iranica, 18, 9-15.

Arabzadeh, A., Soltani, M., \& Ayazi, A. (2011b). Experimental investigation of composite shear wall sundershearloadings. Thin-Walled Structures, 49, $842-854$.

Astaneh-Asl, A. (1998). Seismic studies of innovative and traditional composite shear walls. Research project in progress. Dept. of Civil and Env. Engineering, Univ. of California, Berkeley.

Ayazi, A., Ahmadi, H., \& Shafaei, S. (2012). The effects of bolt spacing on composite shear wall behavior. World Academy of Science Engineering and Technology, 6, 10-27.

Memarzadeh, P. (2009). Theoretical investigation on unstiffened thin steel plate shear wall (Doctoral dissertation). Isfahan University of Technology, Isfahan, Iran.

Memarzadeh, P., Azhari, M., \& Saadatpour, M. M. (2010). A parametric study on buckling loads and tension field stress patterns of steel plate shear walls concerning buckling modes. Steel and Composite Structures, 10(1), 87-108.

Qin, R., Lanhui, G., Feng, F., \& Sumei, Z. (2011). Seismic Behavior of Composite Frame Infilled Composite Steel Plate Shear Walls. IEEE, $1634-1638$. DOI: 10.1109/CECNET.2011.5769262.

Rahai, A., \& Hatami, F. (2009). Evaluation of composite shear wall behavior under cyclic loadings. Journal of Constructional Steel Research, 65, 15281537.

Sanchez, I., Oshiro, A., Positieri, M. (2014). The use of recycled plastic in concrete. An alternative to reduce the ecological footprint. Revista de la Construcción, 13(3), $19-26$

Sun, F.F., Liu, G.R., \& Li, G.Q. (2008). An Analytical Model for Composite Steel Plate Wall. The 14 ${ }^{\text {th }}$ World Conference on Earthquake Engineering. Beijing, China.

Tipping, S., \& Stojadinovic, B. (2008). Innovative corrugated steel shear walls for multi-story residential buildings. $14^{\text {th }}$ World Conference on Earthquake Engineering, Beijing, 05-06-0105.

Vian, D., \& Bruneau, M. (2006). Testing of special LYS steel plate shear walls. $4^{\text {th }}$ International Conference on Earthquake Engineering, Taipei, 158.

Vatansever, C., \& Yardimci, N. (2011). Experimental investigation of thin steel Plate shear walls with different infill-to-boundary frame connections. Steel and Composite Structures, 11(3), 251-271.

Zhao, Q., \& Astaneh-asl, A. (2004). Cyclic behavior of traditional and innovative composite shear walls. $13^{\text {th }}$ World Conference on Earthquake Engineering, Vancouver, 2578.

Zhao, Q. \& Astaneh-asl, A. (2007). Seismic behavior of composite shear wall systems and application of smart structures technology. International journal of steel structures, 7, 69-75. 